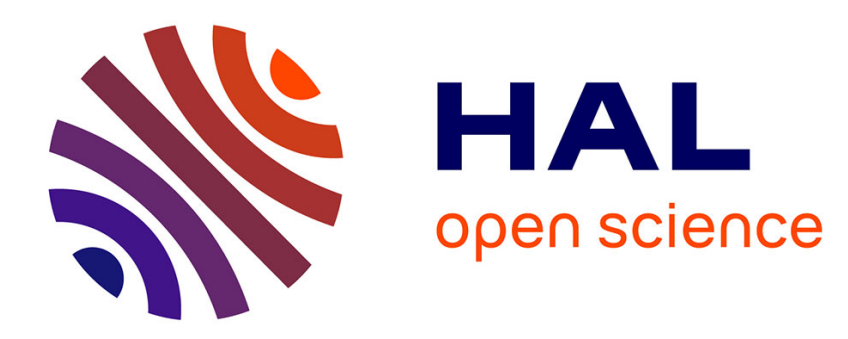

\title{
Reconstructive surgery in young women with breast cancer
}

\author{
Martina Marín-Gutzke, Alberto Sánchez-Olaso
}

\section{To cite this version:}

Martina Marín-Gutzke, Alberto Sánchez-Olaso. Reconstructive surgery in young women with breast cancer. Breast Cancer Research and Treatment, 2010, 123 (s1), pp.67-74. 10.1007/s10549-010-11271. hal-00567227

\section{HAL Id: hal-00567227 https://hal.science/hal-00567227}

Submitted on 19 Feb 2011

HAL is a multi-disciplinary open access archive for the deposit and dissemination of scientific research documents, whether they are published or not. The documents may come from teaching and research institutions in France or abroad, or from public or private research centers.
L'archive ouverte pluridisciplinaire HAL, est destinée au dépôt et à la diffusion de documents scientifiques de niveau recherche, publiés ou non, émanant des établissements d'enseignement et de recherche français ou étrangers, des laboratoires publics ou privés. 
Manuscript Type: Brief article

\section{Reconstructive surgery in young women with breast cancer}

Martina Marín-Gutzke ${ }^{1}$

${ }^{1}$ Hospital Universitario Ramón y Cajal, Madrid, Spain.

Corresponding author:

Martina Marín-Gutzke, MD

Department of Plastic and Reconstructive Surgery

Hospital Universitario Ramón y Cajal

Carretera Colmenar Viejo KM 9,100

28049-Madrid. Spain

E-mail: $\quad$ maringutzke@yahoo.com

Phone: $\quad$ +34 913368533

Fax: $\quad$ +34 $\quad+13580614$ 


\section{Introduction}

Mastectomy is associated with significant treatment-related distress and changes in body image and sexuality due to disfigurement and sense of loss. These effects may be more pronounced in younger women [1, 2]. Breast reconstruction is the reverse of mastectomy, and its main objective is to restore the patient's body image, psychological well-being and expectations after mastectomy.

Autologous and prosthetic (or nonautologous) reconstruction are the two main techniques used for breast reconstruction [3]. Because postoperative outcomes currently obtained with both methods are comparable, the key to fulfilling the primary objective is to individualize patient selection. Factors that are relevant in the process of choosing the best technique for each patient include physician counseling, type of tumor, stage, size, uni- or bilateral involvement, use of adjuvant radiotherapy, body characteristics, overall health, breast cancer treatment plan, personal preferences and age [4]. It has been shown that patients under 50 years of age have a 4.3-fold greater likelihood of undergoing mastectomy followed by breast reconstruction than older patients [5]. The reasons behind this include the desire to achieve adequate breast cosmesis and symmetry, as well as fear of recurrence due to the fact that breast tumors in young women are more likely to be associated with high-risk tumor features and poorer prognosis, and tend to present with a more advanced stage at diagnosis [6].

Radiotherapy deserves special attention because it is being used with increasing frequency in selected patients with early breast cancer. Prosthetic reconstruction in patients receiving adjuvant radiotherapy is problematic; hence, autologous tissue is preferable to breast implants within an irradiated operative field. However even autologous tissue reconstructions can be adversely affected by postmastectomy radiotherapy [7]. 
Prophylactic mastectomy is also being indicated in a growing number of patients with genetic mutations, in cases of lobulillar carcinoma or due to cancer phobia, making bilateral reconstruction an emergent scenario in young women with breast cancer. In these patients it is important to choose a similar reconstructive procedure on both sides to achieve breast symmetry.

Expectations of breast reconstruction are specifically related to breast size and shape, but also to the symmetry of the reconstructed breast with respect of the contralateral nonreconstructed breast, as the latter one will probably suffer changes throughout life.

\section{Prosthetic breast reconstruction}

This method of reconstruction involves placement of silicone gel or saline breast implants. The best results are achieved in patients in whom the breast volume is moderate, there is minimal ptosis, and there is adequate and healthy soft tissue coverage over the device. Patients who have large or ptotic breasts typically require matching procedures, namely reduction mammaplasty and mastopexy, respectively. This problem is simplified in patients undergoing bilateral or prophylactic mastectomies, in which symmetry is more readily achieved.

The advantages of implant-based reconstruction are that it combines a relatively minor procedure with excellent cosmetic results, uses adjacent tissues of similar color, texture, and sensation, obviates distant donor-site-related morbidity, requires less surgical and post-operative recovery times, and saves autologous tissue for a later occasion [8].

Breast reconstruction can be performed either in a single or in a two-stage reconstruction. The first approach involves the immediate placement of a permanent or adjustable implant [9]. Advantages of an adjustable implant over a permanent one are that it may be gradually filled to the desired volume postoperatively, and that patients do not have to undergo two surgical procedures. Nevertheless, it requires the 
placement of a remote port (to fill the implant) which needs to be subsequently removed [9].

The two-stage reconstruction involves placement of a tissue expander within a submuscular pocket during the primary procedure, followed by its replacement with a permanent implant during a second surgical procedure (Figure 1). The tissue expander is inflated at weekly intervals by percutaneous injection of saline solution, allowing the expansion of the skin covering the expander [10]. Although the earliest prosthetic breast reconstructions were carried out in a single stage, nowadays two-stage expander-implant reconstructions are preferred because they are generally believed to produce superior results [8]. Potential complications of a prosthetic breast reconstruction include hematoma, seroma, implant extrusion, infection, rupture and capsular contraction [9].

\section{Autologous breast reconstruction}

This method uses the patient's own tissue to reconstruct the breast, and includes several techniques. The main advantage of autologous breast reconstruction is that results are more natural in terms of appearance, long-term durability and touch. Major disadvantages are the long surgical times, arduous recovery and higher risk of complications. The most frequent donor sites are the lower abdomen and the back. Other flap donor sites include buttocks, back and thighs.

\section{Abdominal donor site}

The lower abdomen provides enough soft tissue bulk for reconstruction of the breast mound, without the need for implants. However, particularly in young women it is essential to consider the possibility of future pregnancies and exercise as a possible cause of abdominal wall morbidity. Flaps can be either pedicled (transverse rectus abdominis muscle [TRAM] flaps) or free (free TRAM, deep inferior epigastric perforator 
[DIEP] and superficial inferior epigastric artery [SIEA] flaps, which progressively spare more muscle) [9]. Besides patient preferences, the choice of the donor site or type of flap largely depends on the amount of abdominal fat and skin available and the presence of contraindications, relative or absolute, such as history of previous abdominal surgery, obesity, smoking, history of blood clots and other major systemic medical conditions [10].

\section{TRAM flap}

This procedure uses abdominal muscle, fat and skin tissue vascularized by the rectus muscle pedicle to reconstruct the breast mound. Grossly, in the pedicled TRAM flap excess skin, subcutaneous fat and rectus muscle from the infraumbilical area are transferred through a subcutaneous tunnel to the ipsilateral [11] or contralateral mastectomy site. The flap is then rotated, shaped into a breast mound, and sutured; the umbilicus and the abdominal skin are sutured into its new position and the abdomen skin is sutured as in an abdominoplasty (Figure 2) [12]. Despite the loss of muscle function after a pedicled TRAM flap harvest, it is still possible for patients to become pregnant and carry a pregnancy to term, as well as to achieve a normal vaginal delivery [13].

\section{Free TRAM flap}

In the free TRAM flap the skin, subcutaneous fat, deep inferior epigastric artery and a small portion of the rectus muscle and fascia from the infraumbilical area are transferred to the chest defect, were epigastric vessels are reattached to either thoracodorsal or internal thoracic vessels via microsurgery (Figure 3) [12]. This technique allows the relocation of larger amounts of tissue with a lesser risk of fat necrosis. Hence it may be a better procedure in patients with risk factors such as smoking, diabetes mellitus and obesity [9]. 


\section{DIEP and SIEA flaps}

These two techniques involve the use of skin and subcutaneous fat free flaps. The free DIEP flap uses perforator vessels from the inferior epigastric artery for vascular supply, thereby preserving rectus muscle continuity (Figure 4) [9]. From an aesthetic point of view, results are essentially the same between the DIEP and the free TRAM flap, however data regarding flap-related complications or donor-site morbidity are conflicting, with some studies showing that DIEP flaps produce less abdominal morbidity and postoperative pain, a quicker recovery and a shorter hospital stay [14], but others indicating no significant differences in these aspects between both techniques [15]. However, important differences regarding abdominal wall function have been observed in favor of free TRAM and DIEP flaps over the pedicled TRAM flap [16]. Computed tomography angiography is now widely used to assess perforator vessels and aid in surgical planning (Figure 5). Dominant perforators with shorter intramuscular course should be selected.

The SIEA flap is the least invasive method of all lower abdominal flap breast reconstructions. It uses the SIEA for vascular supply and does not require dissection of the rectus muscle and fascia, potentially eliminating abdominal donor site morbidity [17]. However, superficial inferior epigastric vessels are only present in approximately $50 \%$ of the population [9].

\section{Dorsal donor site}

\section{Latissimus dorsi (LD) flap}

Almost any patient is a potential candidate for a LD flap due to its reliable vascularization. This flap can be used in patients who would normally be at risk for complications associated with reconstructions using abdominal flaps, such as patients with diabetes mellitus, hypertension, smokers or who are obese [18], after a failed 
implant or TRAM reconstruction, or when previous abdominal surgeries have been carried out, including abdominoplasty. However, the amount of tissue available to reconstruct the breast is often insufficient, requiring the use of tissue expanders and implants [10].

In this technique, the LD is rotated on its thoracodorsal neurovascular pedicle and humeral insertion, tunneled subcutaneously to the mastectomy defect and sutured to the pectoralis major muscle and inframmamary fold (Figure 6) [12]. The advantage of this flap is that it provides padding for the mastectomy defect and softens the contours of the reconstructed breast, thus creating a natural appearance with the placement of an implant.

Current modifications in the surgical technique have significantly improved the consistency and quality of the aesthetic results, thereby making the LD flap an appealing breast reconstruction option for young women with breast cancer [19].

When carrying out a reconstruction using an LD flap, it is preferable to perform a twostage reconstruction by placing an expander, and then replacing it with an anatomical permanent implant after the expansion has been completed [20].

The two-stage procedure has been shown to reduce the rate of capsular contracture from $21-75 \%$ to $3,5-16 \%$ [20-22]. In cases of bilateral mastectomy reconstruction in young and slim women, the LD flap provides an ideal option, with an adequate symmetry (Figure 6). Ischemic complications are uncommon in reconstructions using LD flaps. Seroma formation on the back (18-34\%) is treated with prolonged suction drainage and thoracic compression garments [20, 22]. In some cases, an outpatient percutaneous aspiration may be necessary.

\section{Timing of breast reconstruction after mastectomy}


Timing of breast reconstruction involves several factors, but largely depends on the need for postmastectomy radiotherapy. Radiotherapy increases by more than $40 \%$ the risk of complications in prosthetic-based reconstructions, such as capsular contracture and extrusion [7]. Irradiation of autologous tissue flaps can also lead to skin contracture, fat necrosis and atrophy, resulting in distortion of the reconstructed breast [9]. The LD flap is not resistant to the effects of radiation, and may become atrophic and firm after radiotherapy [18].

On the other hand, even with modern radiotherapy techniques prosthetic or autologous reconstructions can limit the amount of radiation delivered to target tissues, and thus decrease radiotherapy efficacy [7]. Every effort must be made to determine the need for radiotherapy before immediate breast reconstruction in order to avoid these potentially unwanted results.

The two timing options are immediate and delayed. Immediate breast reconstruction, which is performed at the time of mastectomy, produces the best aesthetic outcome, since it allows for preservation of the breast skin envelope and sometimes even the nipple-areola complex. Furthermore, there is the psychological benefit of having a reconstructed breast upon awakening from mastectomy as well as the need for fewer surgical operations [23]. Immediate reconstruction is an oncologically safe option and does not delay the initiation of adjuvant chemotherapy [24, 25].

This procedure is indicated in patients who will almost certainly not require adjuvant radiotherapy, i.e. women with stage I or stage II breast cancer with a low risk of requiring adjuvant radiotherapy [23]. Unfortunately, this risk cannot be predicted, and an increasing number of patients with earlier stage cancer are receiving adjuvant radiotherapy due to the proven benefits in terms of loco-regional control and overall survival [26]. 
Delayed breast reconstruction is indicated in women who will require adjuvant radiotherapy. In these women, the breast should be reconstructed using an autologous breast reconstruction with, for example, a TRAM or LD flap.

To optimize reconstruction in patients at risk of requiring postmastectomy radiotherapy (stage $\mathrm{II}$ ), it is possible to carry out a delayed-immediate reconstruction. With this approach, patients who do not require radiotherapy may benefit from the advantages of a skin-sparing mastectomy while obtaining similar aesthetic outcomes to those of an immediate reconstruction. On the other hand, patients who require radiotherapy may avoid the potential aesthetic complications associated with irradiation after immediate breast reconstructions [27].

The purpose of a delayed-immediate breast reconstruction is to preserve the breast skin envelope while avoiding radiotherapy-related complications associated with breast irradiation after an immediate breast reconstruction. Hence, patients who require adjuvant radiotherapy, as well as those who do not, can achieve aesthetic results [23]. This approach is also done in a two-stage fashion, but the tissue expander is placed completely filled at the time of mastectomy, pending final pathology results. If no radiotherapy is needed, replacement with an implant or autolougous tissue can be carried out within the next 1 or 2 weeks. If radiotherapy is required, the expander is deflated to optimize irradiation of the internal mammary nodes. After completion of radiotherapy, the patient undergoes reexpansion of the preserved breast skin and subsequent autologous reconstruction [23].

\section{Partial mastectomy reconstruction}

Conservative surgery followed by radiotherapy has replaced modified radical mastectomy as the preferred treatment for early stage invasive breast cancer. Partial mastectomy preserves the nipple and areola complex (NAC), although in some cases breast asymmetry and distortion can occur. The effects of radiotherapy add to the 
complexity of these cases. Approximately $10 \%$ to $30 \%$ of patients are dissatisfied with the aesthetic following partial mastectomy and radiotherapy. The causes of aesthetic failure are tumor resection with noticeable volume changes, distortion of the position of the NAC, and the effects of radiation per se [28].

Partial mastectomy reconstruction can also be immediate or delayed. In the immediate reconstruction we try to avoid breast deformities by reconstructing the defect at the same surgical time as the mastectomy. The combination of partial mastectomy and immediate partial breast reconstruction is known as oncoplastic surgery. By performing a reduction mammoplasty-type procedure during the tumor resection surgery, a more aesthetic postoperative breast is obtained. The pattern can then be rotated laterally or medially to fit the location of the tumor (Figure 7) [28].

In a delayed partial breast reconstruction, the surgeon's efforts are directed towards correcting the breast deformity after completion of radiotherapy. The best aesthetic results are achieved when autologous tissues, such as the LD or TRAM flaps described above, are used (Figure 8) [28].

\section{Conclusions}

In young patients who undergo mastectomy, recovery of body image is essential for physical and mental quality of life. Young women with breast cancer have specific characteristics related to the age of onset of the disease; diagnosis is frequently established at a more advanced stage, and reconstructive expectations are largely related to breast size, shape, and symmetry of the reconstructed breast with regards to the contralateral non-reconstructed breast and the changes it may suffer throughout life.

Patient individualization is the key to a successful breast reconstruction and essential to meeting the patient's expectations after mastectomy. Each reconstructive technique has its own indications, advantages and limitations, which must be openly and 
thoroughly discussed with the patient. Timing of the surgery is primarily determined by the requirement for adjuvant radiotherapy. If the risk of requiring adjuvant radiotherapy is low, an immediate reconstruction is the method of choice. In patients with a high risk of requiring adjuvant radiotherapy, a delayed approach is recommended, and in patients in whom the need for adjuvant radiotherapy is in doubt, a delayed-immediate approach is the best to optimize aesthetic and oncologic outcomes. 


\section{Acknowledgements}

The authors acknowledge the support of Pfizer Spain, which facilitated the necessary meetings to evaluate and discuss all the data presented in this review, and Dr. Ximena Alvira from HealthCo SL (Madrid, Spain) for assistance in the preparation of this manuscript. 


\section{References}

1. Schover LR (1994) Sexuality and body image in younger women with breast cancer. J Natl Cancer Inst Monogr (16):177-82

2. Fobair P, Stewart SL, Chang S, D'Onofrio C, Banks PJ, Bloom JR (2006) Body image and sexual problems in young women with breast cancer.

Psychooncology 15:(7):579-94

3. Disa JJ, McCarthy CM, Mehrara BJ, Pusic AL, Hu QY, Cordeiro PG (2009) Postmastectomy reconstruction: an approach to patient selection. Plast Reconstr Surg 124:(1):43-52

4. Nahabedian MY (2009) Breast reconstruction: a review and rationale for patient selection. Plast Reconstr Surg 124:(1):55-62

5. Morrow M, Scott SK, Menck HR, Mustoe TA, Winchester DP (2001) Factors influencing the use of breast reconstruction postmastectomy: a National Cancer Database study. J Am Coll Surg 192:(1):1-8

6. Peppercorn J (2009) Breast cancer in women under 40. Oncology (Williston Park) 23:(6):465-74

7. Kronowitz SJ, Robb GL (2009) Radiation therapy and breast reconstruction: a critical review of the literature. Plast Reconstr Surg 124:(2):395-408

8. Spear SL, Mesbahi AN (2007) Implant-based reconstruction. Clin Plast Surg 34:(1):63-73; abstract vi

9. Reavey P, McCarthy CM (2008) Update on breast reconstruction in breast cancer. Curr Opin Obstet Gynecol 20:(1):61-7

10. Djohan R, Gage E, Bernard S (2008) Breast reconstruction options following mastectomy. Cleve Clin J Med 75 Suppl 1:S17-23

11. Marín-Gutzke M, Sánchez-Olaso A, Fernández-Camacho FJ, Mirelis-Otero E (2005) Anatomic and clinical study of rectus abdominis musculocutaneous flaps 
based on the superior epigastric system: ipsilateral pedicled TRAM flap as a safe alternative. Ann Plast Surg 54:(4):356-60

12. Cordeiro PG (2008) Breast Reconstruction after Surgery for Breast Cancer. N Engl J Med 359:(15):1590-1601

13. Chen L, Hartrampf CR, Jr., Bennett GK (1993) Successful pregnancies following TRAM flap surgery. Plast Reconstr Surg 91:(1):69-71

14. Blondeel PN (1999) One hundred free DIEP flap breast reconstructions: a personal experience. Br J Plast Surg 52:(2):104-11

15. Bajaj AK, Chevray PM, Chang DW (2006) Comparison of donor-site complications and functional outcomes in free muscle-sparing TRAM flap and free DIEP flap breast reconstruction. Plast Reconstr Surg 117:(3):737-46; discussion $747-50$

16. Atisha D, Alderman AK (2009) A systematic review of abdominal wall function following abdominal flaps for postmastectomy breast reconstruction. Ann Plast Surg 63:(2):222-30

17. Wu LC, Bajaj A, Chang DW, Chevray PM (2008) Comparison of donor-site morbidity of SIEA, DIEP, and muscle-sparing TRAM flaps for breast reconstruction. Plast Reconstr Surg 122:(3):702-9

18. Hammond DC (2007) Latissimus dorsi flap breast reconstruction. Clin Plast Surg 34:(1):75-82; abstract vi-vii

19. Hammond DC (2009) Latissimus dorsi flap breast reconstruction. Plast Reconstr Surg 124:(4):1055-63

20. Sternberg EG, Perdikis G, McLaughlin SA, Terkonda SP, Waldorf JC (2006) Latissimus dorsi flap remains an excellent choice for breast reconstruction. Ann Plast Surg 56:(1):31-5 
21. McCraw JB, Maxwell GP (1988) Early and late capsular "deformation" as a cause of unsatisfactory results in the latissimus dorsi breast reconstruction. Clin Plast Surg 15:(4):717-26

22. Spear SL, Boehmler JH, Taylor NS, Prada C (2007) The role of the latissimus dorsi flap in reconstruction of the irradiated breast. Plast Reconstr Surg 119:(1):1-9; discussion 10-1

23. Kronowitz SJ, Kuerer HM (2006) Advances and surgical decision-making for breast reconstruction. Cancer 107:(5):893-907

24. Taylor CW, Horgan K, Dodwell D (2005) Oncological aspects of breast reconstruction. Breast 14:(2):118-30

25. Ananthakrishnan $P$, Lucas A (2008) Options and considerations in the timing of breast reconstruction after mastectomy. Cleve Clin J Med 75 Suppl 1:S30-3

26. Clarke M, Collins R, Darby S, Davies C, Elphinstone P, Evans E, et al. (2005) Effects of radiotherapy and of differences in the extent of surgery for early breast cancer on local recurrence and 15-year survival: an overview of the randomised trials. Lancet 366:(9503):2087-106

27. Kronowitz SJ (2010) Delayed-immediate breast reconstruction: technical and timing considerations. Plast Reconstr Surg 125:(2):463-74

28. Hamdi M, Wolfli J, Van Landuyt K (2007) Partial Mastectomy Reconstruction. Clinics in Plastic Surgery 34:(1):51 
Figure 1. Two-stage breast reconstruction in a young woman after mastectomy.
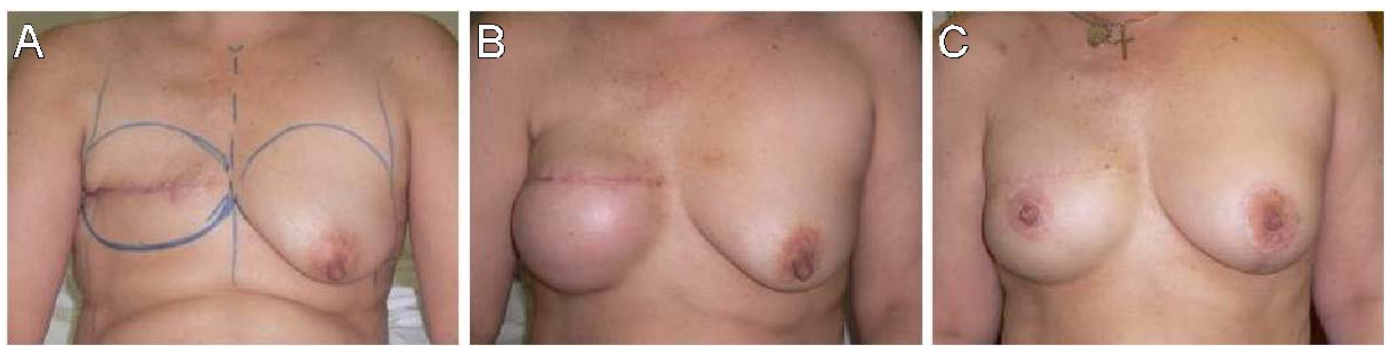

(A) Right postmastectomy view. (B) Postoperative view after placement of tissue expander. (C) Postoperative view after delayed reconstruction, left vertical mastopexy for symmetry and right nippleareola complex reconstruction. 
Figure 2. Breast reconstruction using a pedicled transverse rectus abdominis muscle (TRAM) flap.
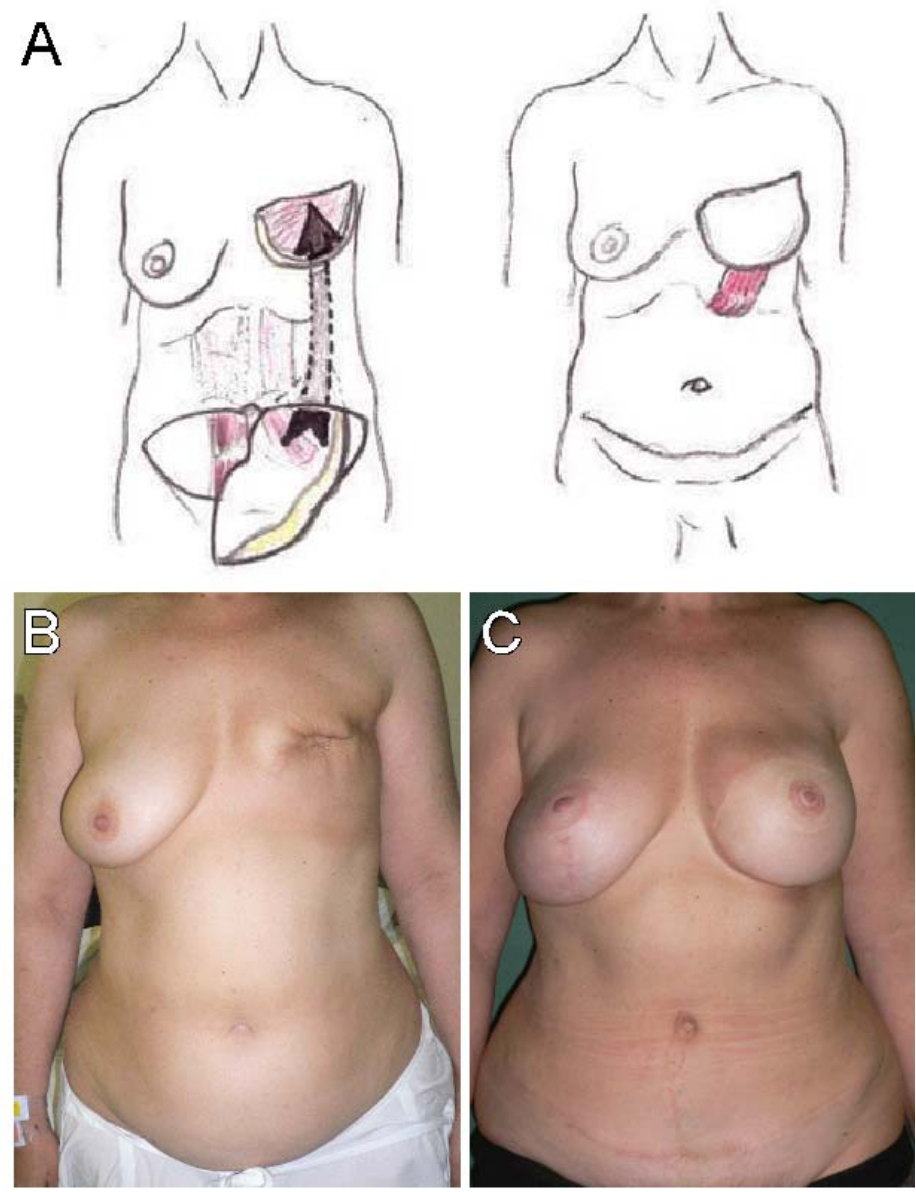

(A) Skin, subcutaneous fat and rectus muscle are transferred subcutaneously to the mastectomy site. (B) Photographs of a young patient who underwent left mastectomy followed by (C) delayed TRAM flap breast reconstruction, and right vertical mastopexy for symmetry. 
Figure 3. Breast reconstruction using a free transverse rectus abdominis muscle (TRAM) flap.

A
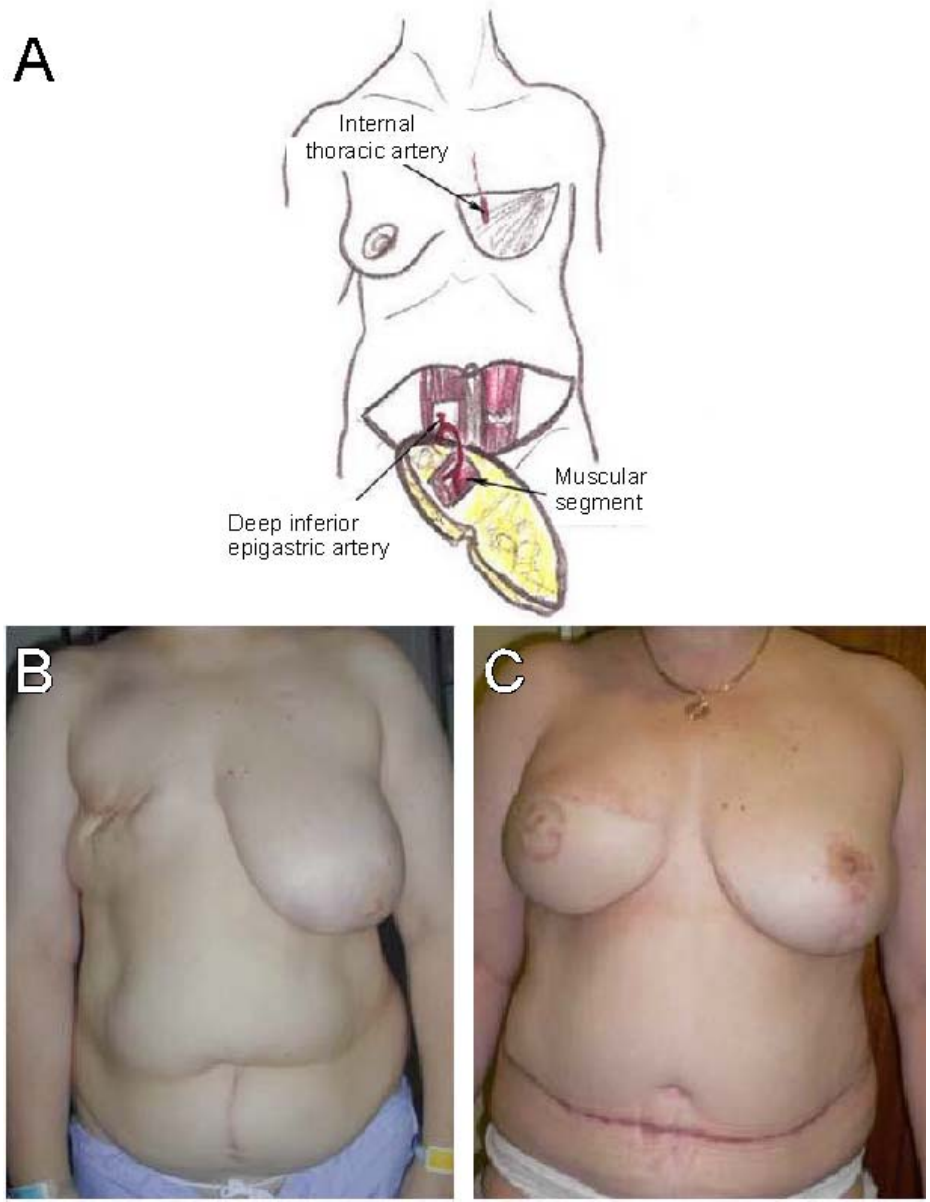

(A) Skin, subcutaneous fat, deep inferior epigastric artery and a small portion of the rectus muscle are transferred subcutaneously to the mastectomy site. (B) Photographs of a young patient who underwent right mastectomy followed by (C) delayed free TRAM flap breast and nipple-areola complex reconstruction, and left vertical mastopexy for symmetry. 
Figure 4. Breast reconstruction using a free deep inferior epigastric perforator (DIEP) flap.

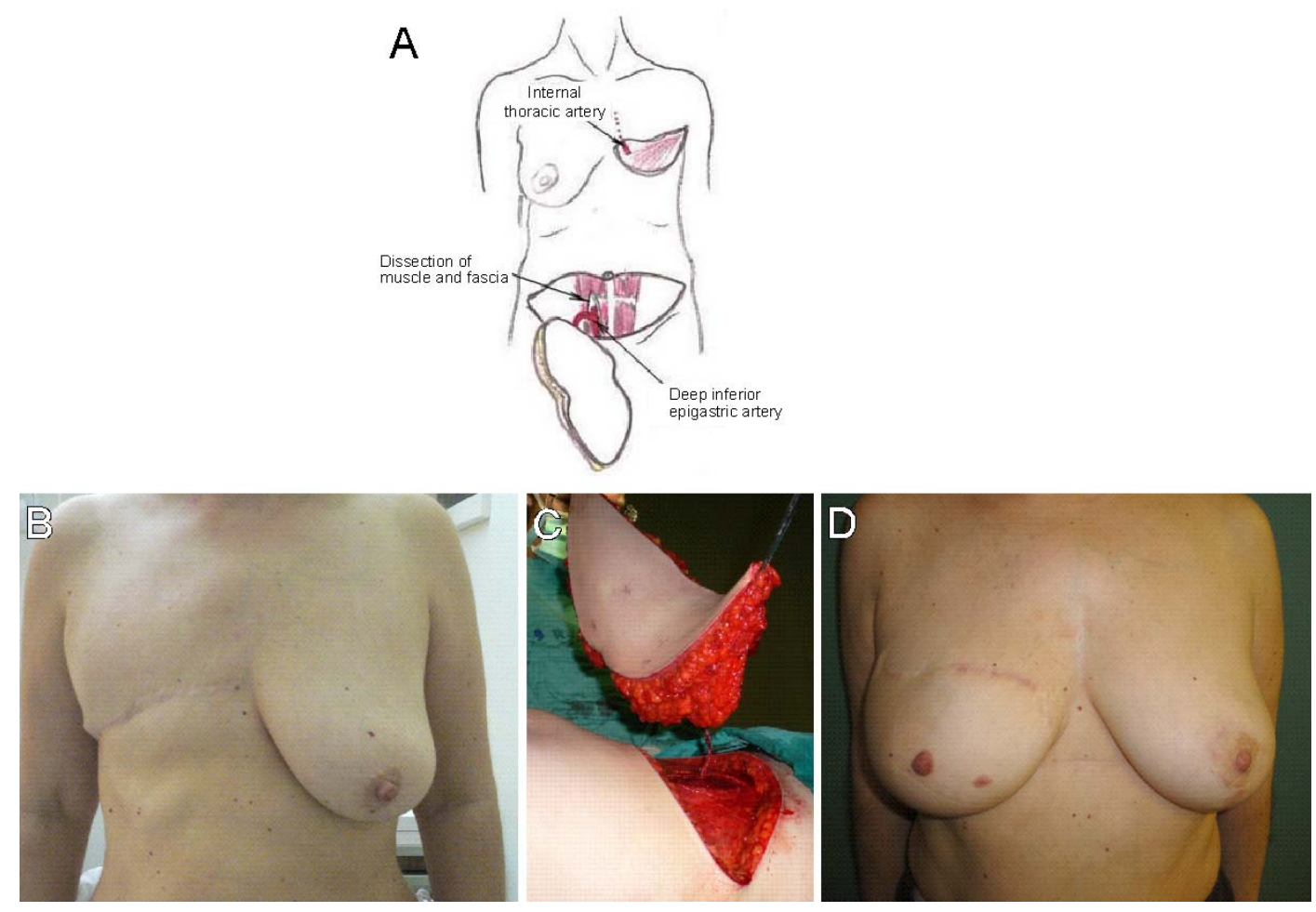

(A) Skin, subcutaneous fat and deep inferior epigastric vessels are transferred to the mastectomy site. (B) Photograph of a young patient who underwent right mastectomy. (C) Intraoperative view of the raised DIEP flap. (D) Delayed free DIEP flap breast and left vertical mastopexy for symmetry. 
Figure 5. Abdominal computed tomography (CT) angiography.

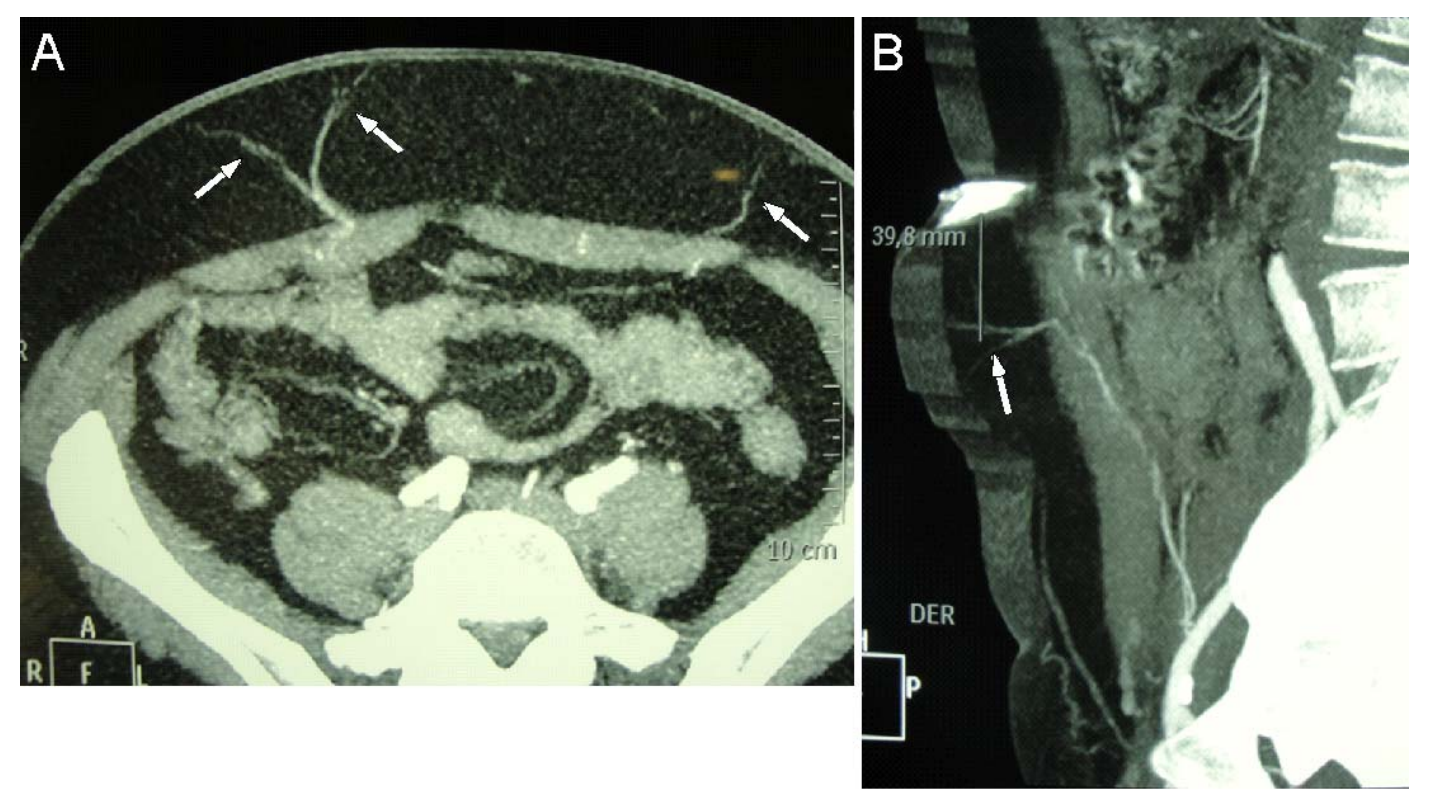

Horizontal (A) and sagittal (B) CT images of the deep epigastric perforator vessels (white arrows) from the inferior epigastric artery, piercing the rectus abdominis muscle to the skin. 
Figure 6. Breast reconstruction using a latissimus dorsi (LD) flap.
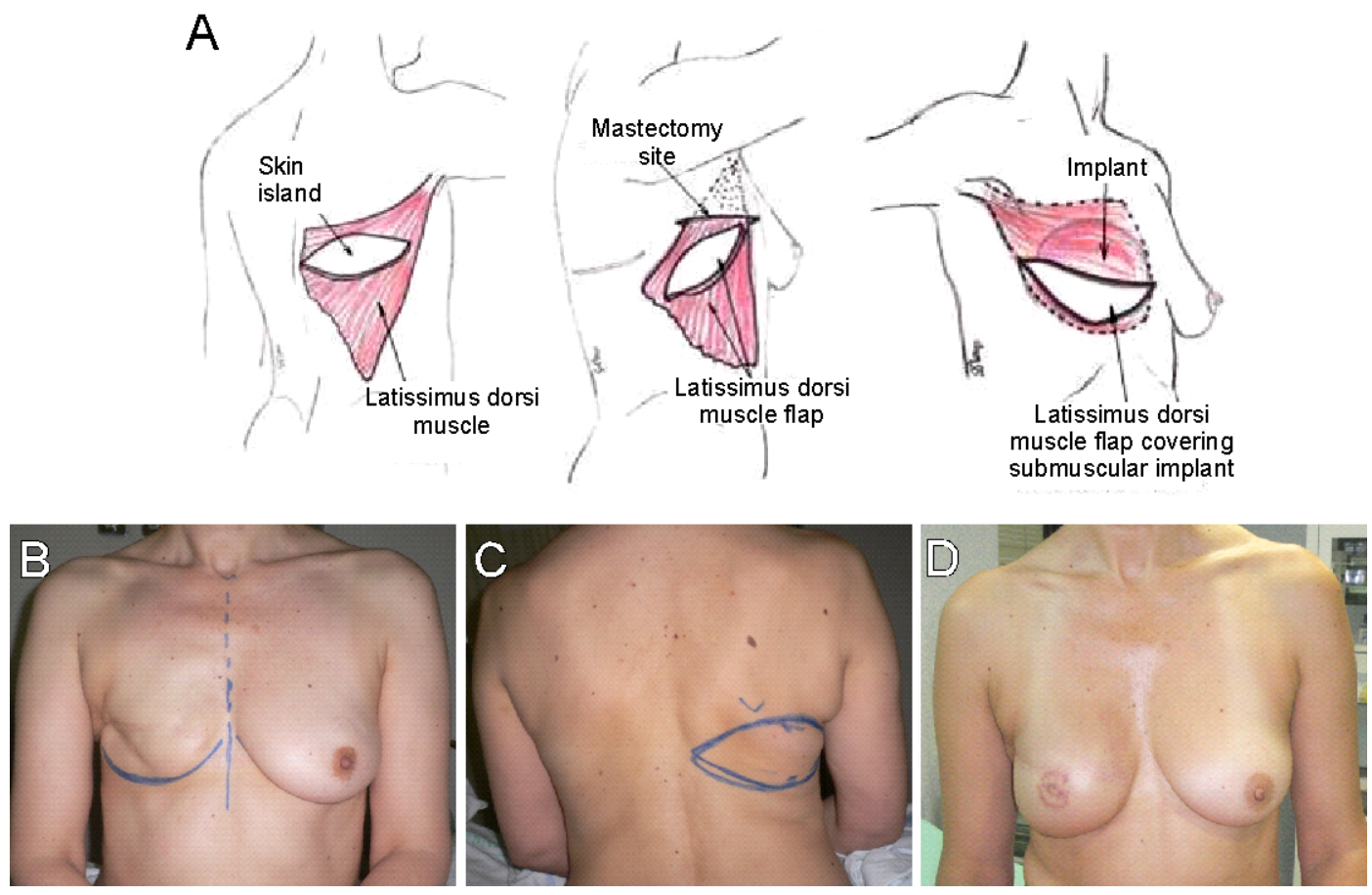

(A) The LD muscle is rotated on its thoracodorsal neurovascular pedicle, tunneled subcutaneously to the mastectomy site, and sutured to the pectoralis major muscle and inframmamary fold, in this case followed by placement of a breast implant. (B) Photograph of a young patient who underwent right mastectomy. (C) Design of the LD skin paddle and (D) delayed LD flap breast reconstruction. 
Figure 7. Oncoplastic surgery.
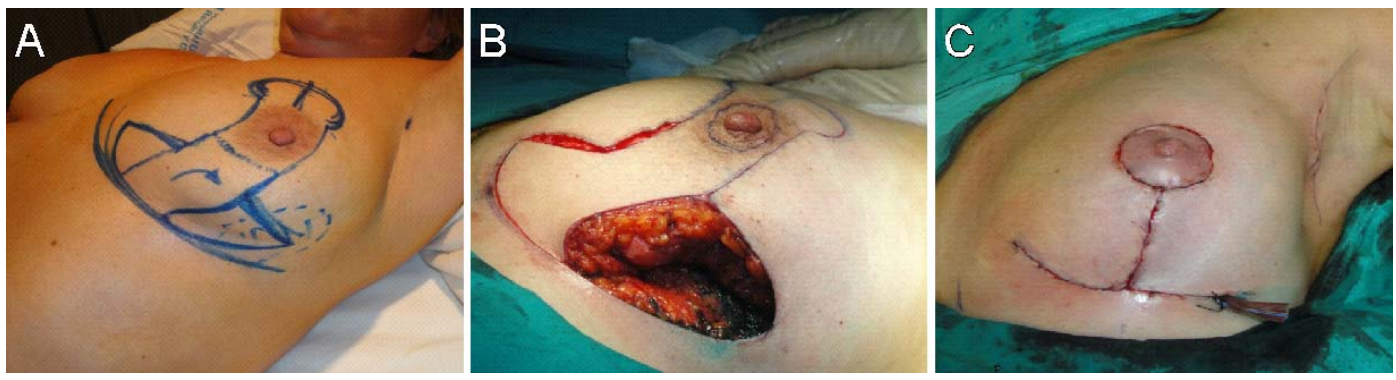

Photographs of a young patient with a breast carcinoma located in the outer lower pole of the left breast. (A, B) Marking of the proposed excision and reduction mammaplasty using an inferior breast flap to fill the defect. (C) Result after immediate breast remodeling. 
Figure 8. Delayed partial breast reconstruction.
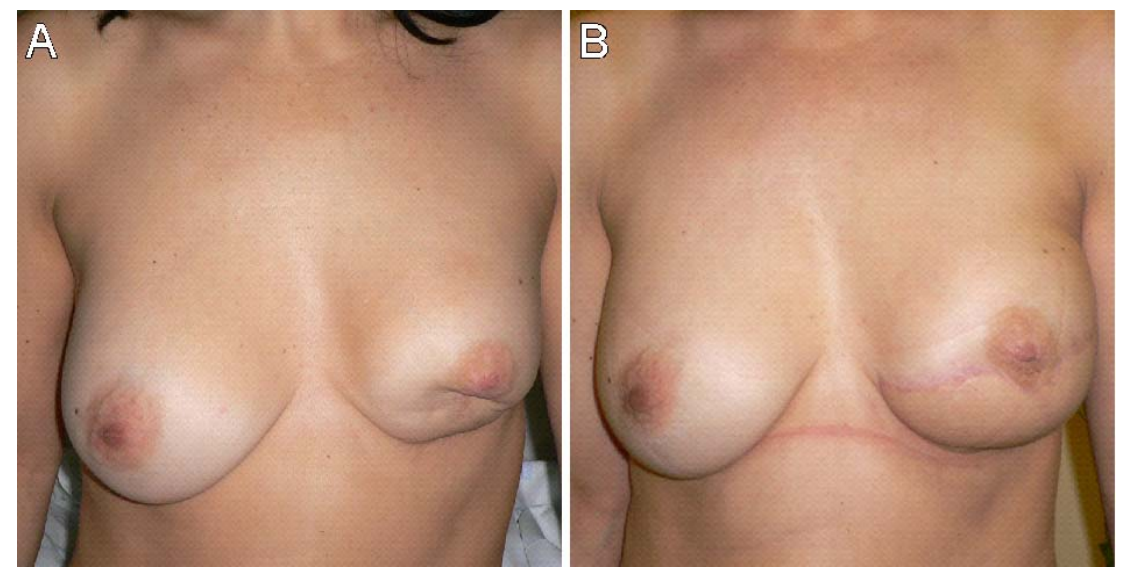

(A) Photograph of a young patient with a partial mastectomy defect in the lower pole of the left breast who underwent conservative surgery and adjuvant radiotherapy for breast carcinoma. (B) Postoperative image after delayed reconstruction using a latissimus dorsi flap. 